\title{
Contingency Analysis of a Power Grid with the Participation of Utility-Scale Solar PV Units: A Case Study from Sarawak, Malaysia
}

\author{
A. Balqis Z. Khan \\ Department of Electrical and Electronic \\ Faculty of Engineering \\ Universiti Malaysia Sarawak \\ Kota Samarahan, Malaysia
}

\author{
Ahmed M. A. Haidar ${ }^{\mathrm{ab}}$ \\ ${ }^{a}$ Universiti Malaysia Sarawak \\ Samarahan, Sarawak, Malaysia \\ bUniversity of Southern Queensland \\ Toowoomba, Queensland, Australia
}

\author{
Al-Khalid bin Hj Othman \\ Department of Electrical and Electronic \\ Faculty of Engineering \\ Universiti Malaysia Sarawak \\ Kota Samarahan, Malaysia
}

\begin{abstract}
Integrating renewable energy resources (RER) into the power grid may jeopardize the whole power system if the penetration level or solar PV uncertainty is not thoroughly managed. The critical impact on the behaviour of power system can be observed during the line outage in a power grid connected with large-scale RER. Therefore, contingency analysis (CA) is crucial to assess such hybrid power grid. This paper proposes a framework based on $\mathrm{CA}$ to assess the simultaneous effect of large-scale solar photovoltaic (PV) power plants integrated with the existing power grid, particularly, in the aspects of implementing effective measuring indices. Simulation studies have been carried out on a practical power system, which was modelled by considering the probability of solar irradiance at different locations in Sarawak. The study presented in this paper can provide an insight to identify the level of insecurity for a large-scale deployment of solar PV systems in Sarawak.
\end{abstract}

Keywords-Contingency analysis, large-scale solar PV system; probability of solar irradiance; performance indices

\section{INTRODUCTION}

The ultimate objective of the power grid is to transport electricity from power plants into the electricity end-users. Generally, the increase in the environmental impact of traditional power plants corresponds to the load growth. As such, the use of RER is one of the optimal choices to reduce the negative effect due to the burning of fossil fuels. From the utility system perspective, RER act as a tool to relieve the transmission constraints and satisfy the load growth. However, an embodied power grid with RER creates challenges and risks that might threaten the whole power system. For instance, an improper location of RER in the power grid may enhance more power losses and reduce the power system reliability [1]. Hence, with the aim of effective RER integration, safety measures are usually considered when selecting the size and location of RER [2].

There are many issues of integrating the RER into the power grid such as; undesirable changes in power quality, voltage profile, system stability, line loading and generation mismatch. These changes somehow have a negative impact on the cost of maintenance, reliability and lifespan of the devices in a power system during contingencies. In addition, a reverse power flow might occur due to the bidirectional nature of the integrated power grid, causing many problems in the operation and control of regulating devices, and the setting of protection relays. On the other hand, an appropriate location and sizing of RER can improve the voltage profile during the peak demand period, and thus, minimising the line

This work has been supported by a grant (F02/FRGS/1497/2016) from the Ministry of Higher Education (Malaysia). loading which in turn will reduce the power losses [3].

The solar PV power plant is also known as a utility-scale PV unit. It is a large-scale PV system (solar farms) designed to supply electricity into the power grid rather than into an isolated local load. Evidently, such systems will become in the future one of the main components in the Malaysian power grid, as the Energy Commission (EC) of Malaysia intends to build large-scale solar PV plants in Peninsular Malaysia and Sabah/Labuan. The EC said in a release that the capacity of solar PV plant is in the range of 1 to $35 \mathrm{MW}$ and expected to be commissioned in $2019-2020$. The target is to generate in total a $460 \mathrm{MW}$ from the installed solar PV plants, $360 \mathrm{MW}$ in Peninsular Malaysia, while in Sabah/Labuan 100 MW [4].

A variety of study efforts concerning the large-scale RER integration with the power system was published during the last years. Due to the growth of RER penetration, the power system needs an additional operating reserve to secure enough power to maintain the flexibility of the integrated power grid. The study in [5] proposed an operational strategy base frequency regulation to attain the flexibility of power grid integrated with utility-scale solar PV units. To enable the optimal operations of RER, authors in [6] provides details on the integration requirements and characterisation of variable renewable energy (VRE) through; energy storage, the utilisation of demand response, non-VRE ramping requirement, VRE curtailment rates, and system costs. A dynamic energy management strategy was proposed in [7] to optimise the large-scale integration, and to ensure the improvement of the operating performance in terms of energy utilisation, power quality, adaptability and autonomy of the distribution system. As reported in [8], an integration of large-scale RER poses fundamental challenges to the power system operation and control of generation. The authors in [8] identified a number of concerns that should be addressed such as; the formation of short-term electricity markets, energy management, renewable energy policies with the Carbon Dioxide reduction, and internationally harmonising the energy policies of the integrated power grid. The usage of utility-scale PV to enhance system frequency with regard to the power grid stability was analysed in [9]. The authors developed an approach to coordinate the voltage and frequency for achieving a dynamic grid support and primary frequency control. The performance of a $10 \mathrm{MW} \mathrm{PV}$ plant integrated with the Indian power grid has been investigated in [10]. The plant was designed to operate with a seasonal tilt, aiming to obtain the required data needed for evaluating the benefits of operating the plant based on the output of the net energy. 